\title{
EMBRYONAL TUMOUR WITH MULTI-LAYERED ROSETTE- A RARE CASE REPORT
}

Nandakumar G1, Nisha Francis², Krishna Govindan Balachandran Nair ${ }^{3}$

1 Professor, Department of Pathology, Government Medical College, Thiruvananthapuram, Kerala, India.

2Junior Resident, Department of Pathology, Government Medical College, Thiruvananthapuram, Kerala, India.

3 Professor and HOD, Department of Pathology, Government Medical College, Thiruvananthapuram, Kerala, India.

HOW TO CITE THIS ARTICLE: Nandakumar G, Francis N, Nair KGB. Embryonal tumour with multi-layered rosette- a rare case report. J. Evolution Med. Dent. Sci. 2019;8(14):1199-1201, DOI: 10.14260/jemds/2019/264

\section{PRESENTATION OF CASE}

An eleven-year-old female child presented with complaints of head ache and vomiting for 1 month. Routine blood examination was within normal limits. MRI shows a heterogenous enhancing lesion of mixed signal density with cystic and solid component involving right frontal lobe extending into the perisylvian region suggestive of PNET/Atypical Teratoid/Rhabdoid Tumour. She underwent excision biopsy from right frontal region

\section{CLINICAL DIAGNOSIS}

Right Frontal PNET

\section{DIFFERENTIAL DIAGNOSIS}

- PNET

- Atypical Rhabdoid Teratoid Tumour

\section{PATHOLOGICAL DISCUSSION}

\section{A. Macroscopy}

Gross of excision biopsy specimen from right frontal region was in multiple grey brown tissue-bits aggregate measurement: $3 \times 2 \times 1 \mathrm{cms}$. Cut section of which was solid grey white and grey brown. Serial sections were similar.

\section{B. Microscopy}

Section shows fragments of a neoplasm with highly cellular area composed of cells arranged in diffuse sheets; multilayered rosette: true rosettes lined by multiple layers of primitive cells were seen (Fig. 1) whose nucleus tend to be pushed away from the rosette and a defined outer membrane is lacking (Fig. 2 and 3); the cells facing the lumen have a defined internal limiting membrane in some rosettes (Fig. 4); Some of these rosettes has empty central lumina; (Fig. 4) Individual cells have scant to moderate eosinophilic cytoplasm; increased nuclear to cytoplasmic ratio; pleomorphic vesicular nuclei; coarse granular chromatin. Few mitotic figures noted. Areas with neuropil like material noted and foci of necrosis also seen.

Immunohistochemical study of neoplastic cells showed diffuse strong positivity for vimentin (Fig. 5), focal positivity for Synaptophysin (Fig. 6), GFAP (Fig.7) and EMA was negative. Correlating the history, site of lesion, radiological findings and the typical histological features we diagnosed it as a case of embryonal tumour with multi-layered rosettes.

'Financial or Other Competing Interest': None.

Submission 18-02-2019, Peer Review 25-03-2019,

Acceptance 01-04-2019, Published 08-04-2019.

Corresponding Author:

Nisha Francis,

C/o. Arnold Raj N. D, Raj Nivas, KERA C-72,

Pallimukku, Peyad P. 0-695573, Kerala, India.

E-mail:nifrancis2016@gmail.com

DOI: $10.14260 /$ jemds $/ 2019 / 264$
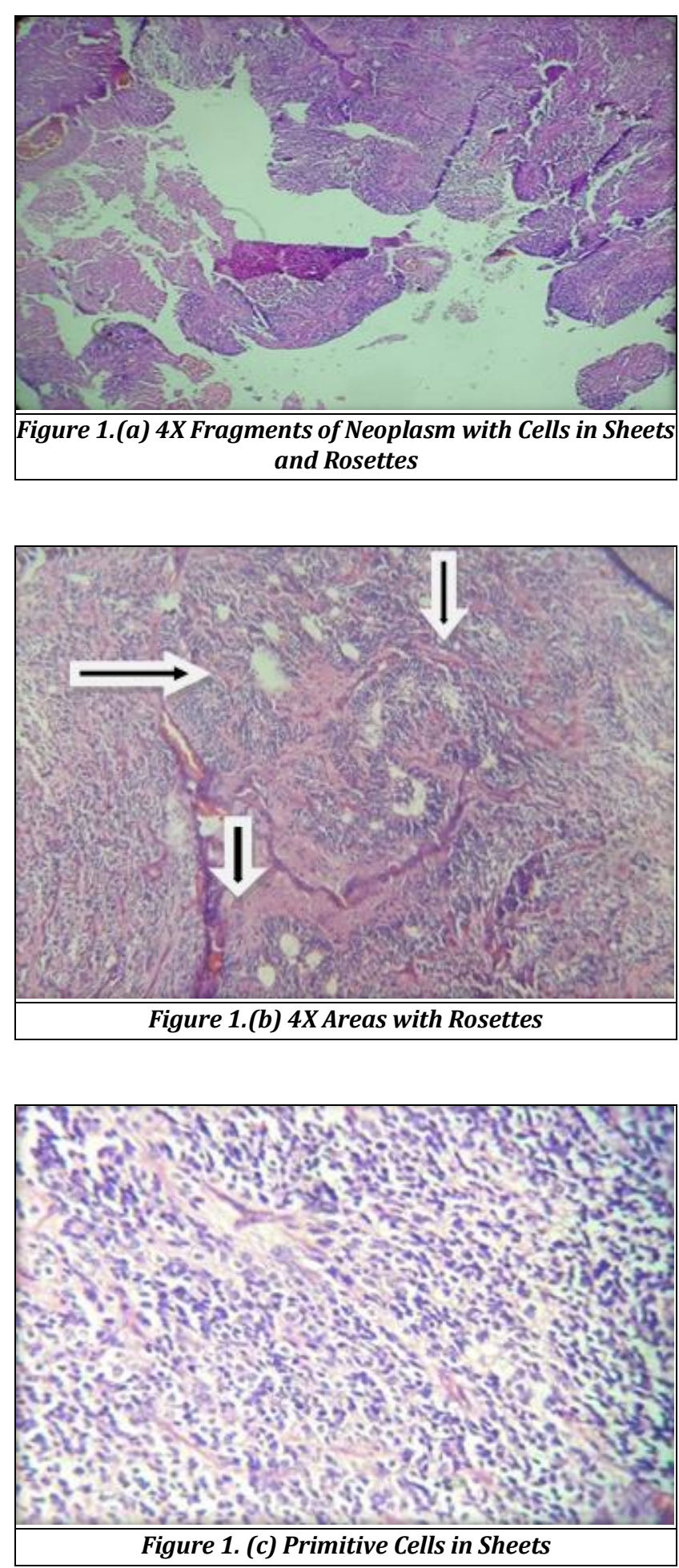

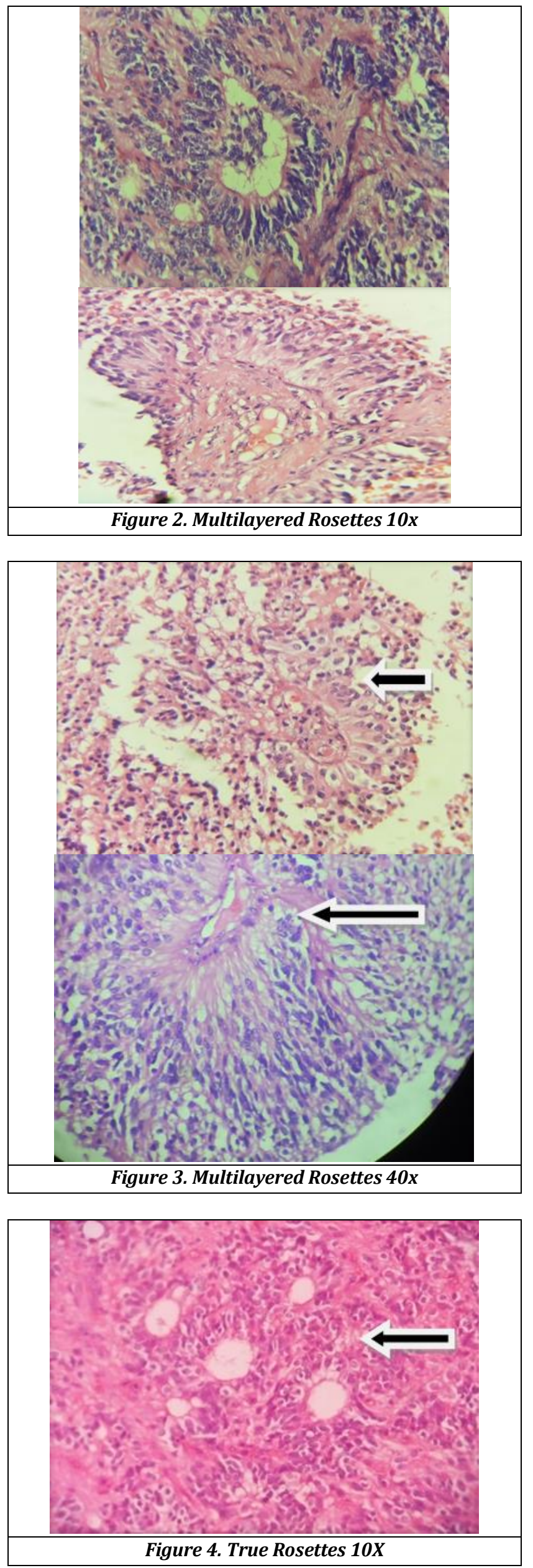
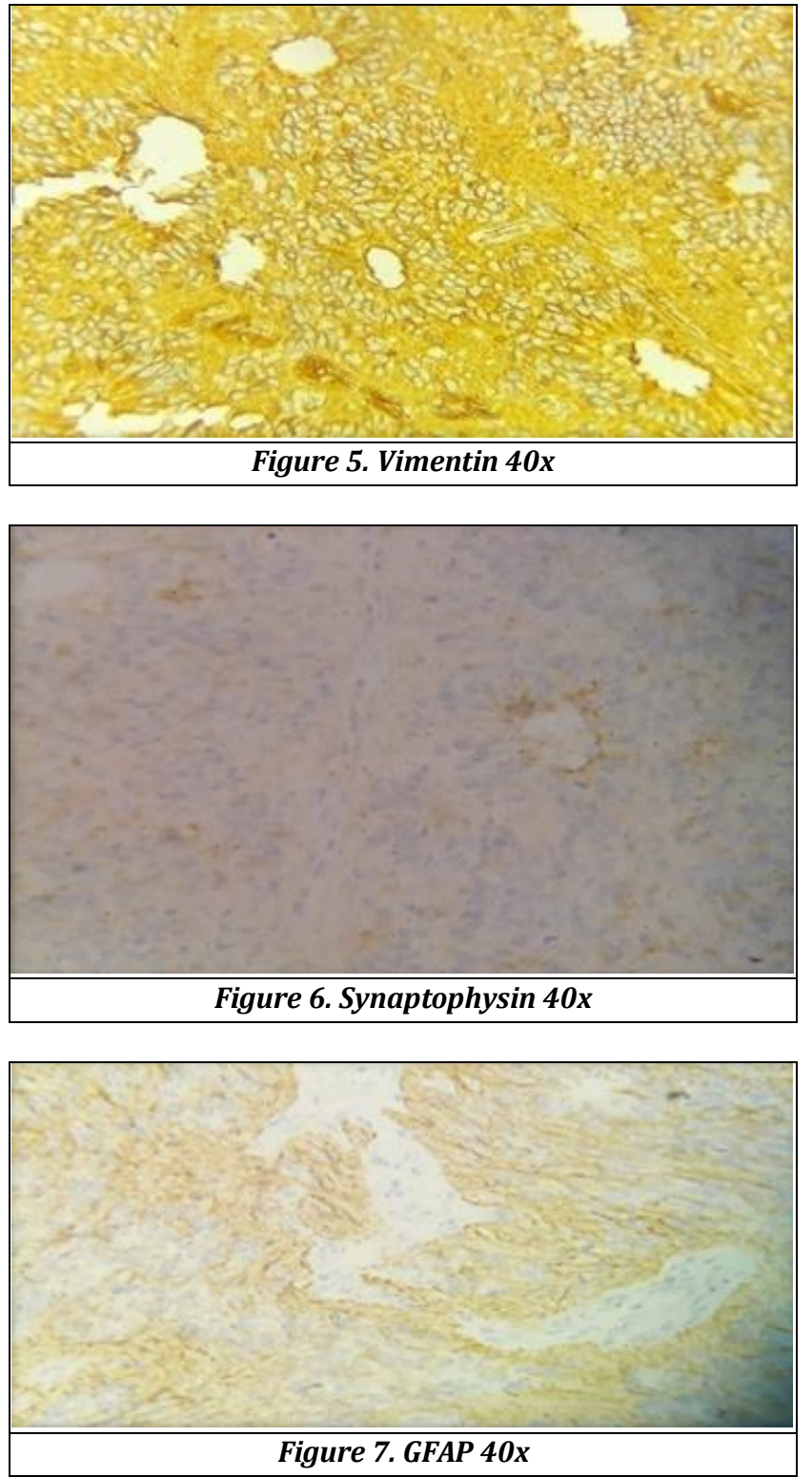

\section{DISCUSSION AND MANAGEMENT}

Embryonal Tumour with Multi-Layered Rosette comes under a group of highly aggressive, malignant tumour most commonly seen in children mostly in first five years $(1,2)$ the frontal lobe. Usually presents with features of increased intra cranial pressure. Histologically ETMR are characterized by undifferentiated neuro epithelial cells resembling those of classic CNS PNET, abundant well differentiated neuropil and ependymoblastic rosettes scattered throughout pauci-cellular region of neoplastic neuropil. Unlike Medulloblastoma, ETMR has no epithelial like formation. Instead it has very characteristics ependymoblastic rosettes in both highly cellular as well as acellular area. Recently amplification of C19MC region on chromosome $19(19$ q 13.42) (3) has been identified as a characteristic of these tumours $(4,5)$. As a result, both ETANTR \& CNS PNET has been removed from 2016 updates of WHO classification of CNS tumour and has been replaced by the term ETMR, C 19 MC- altered or ETMR -NOS if C19MC amplification is absent. In our case molecular testing was not done, but with the characteristic feature of multi-layered rosettes; we place our diagnosis as Embryonal Tumour with Multi-layered Rosette, NOS; WHO Grade 4. LIN 28A; a protein that binds small RNAs, a negative regulator of 
let-7 family of micro RNAs which act as tumour suppressor micro RNAs is now used as an Immunohistochemical marker (6,7). Fusion of C19MC to the TTYH1 gene drives the expression of C19MC microRNAs. C19MC amplification detected by FISH or Array OR fusion RT-PCR can also be done.

\section{Treatment \& Prognosis}

Current treatment options for ETMR include surgical resection systemic chemotherapy and craniospinal radiation (when appropriate). Unfortunately prognosis is dismal $(8,1,7)$ about $75 \%$ of cases died without median survival of 9 months. Our case was referred to higher centre for further management.

\section{FINAL DIAGNOSIS}

Embryonal Tumour with Multi-Layered Rosettes

(WHO Grade IV)

\section{REFERENCES:}

[1] WHO. Classification of Tumours of the Central Nervous System. $4^{\text {th }}$ edn. Revised. Lyon: International Agency for Research Centre 2016.

[2] Neelima R, Easwer HV, Kapilamoorthy TR, et al. Embryonal tumor with multilayered rosettes: Two case reports with a review of the literature. Neurology India 2012;60(1):96-9.
[3] Mozes P, Hauser P, Hortobagyi T, et al. Evaluation of the good tumor response of embryonal tumor with abundant neuropil and true rosettes. Journal of NeuroOncology 2016;126(1):99-105.

[4] Pfister SM, Korshunov A, Kool M, et al. Molecular diagnostics of CNS embryonal tumors. Acta Neuropathologica 2010;120(5):553-66.

[5] Govindan A, Muralikrishnan VP, Alapatt JP. Embryonal tumor with multilayered rosettes in a 3-year-old girl: case report. Turk Neurosurg 2017;8:1.

[6] Omari Y, Karkash AA, Mansour RA, et al. Medulloepithelioma with heterologous osteoid component: a case report and review of literature. Child's Nervous System 2019: p. 1-5.

[7] Wang B, Gogia B, Fuller GN, et al. Embryonal tumor with multilayered rosettes, C19MC-Altered: clinical, pathological, and neuroimaging findings. Journal of Neuroimaging 2018;28(5):483-9.

[8] Kram DE, Henderson JJ, Baig M, et al. Embryonal tumors of the central nervous system in children: the era of targeted therapeutics. Bioengineering (Basel) 2018;5(4):pii: E78. 